\title{
SEGURIDADE SOCIAL NO BRASIL: A BUSCA DO EQUILÍBRIO ENTRE OS OBJETIVOS DA ORDEM SOCIAL E SEU FINANCIAMENTO*
}

\author{
Cristina Aguiar Ferreira da Silva**
}

\section{INTRODUÇÃO}

A Constituinte de 1988, dentro do contexto histórico em que estava inserida, buscou o estabelecimento de um equilíbrio entre as várias dimensões de direito. Como marco representativo do processo de transição do estado de exceção para a democracia, ao mesmo tempo que estabelecia normas para evitar os abusos do Estado, preocupava-se com a crescente desigualdade social que assolava o país.

Assim, é possível identificar, na nova Constituição, tanto a valorização dos direitos fundamentais de primeira dimensão, inerentes ao princípio da liberdade, quanto a garantia de uma igualdade mínima sem a qual as liberdades individuais previstas não poderiam ser exercidas adequadamente.

Essa preocupação com os direitos de igualdade, inerentes aos direitos fundamentais de segunda dimensão, é abordada no texto constitucional com a busca do equilíbrio necessário para a efetivação da dignidade da pessoa humana.

Não se deve ignorar, entretanto, que o estabelecimento de ampla proteção social pela Carta Constitucional de 1988 resulta na necessidade da instrumentalização de políticas para a concretização dos direitos, exigindo recursos decorrentes das receitas auferidas pelo Estado, em especial, os oriundos da arrecadação tributária. A identificação do ponto de equilíbrio entre a proteção social e seu financiamento é o objeto do presente estudo, que tem como foco a Seguridade Social por estar na base da ideia de ordem social e abarcar as políticas públicas que demandam mais recursos financeiros para sua viabilização.

\footnotetext{
*Artigo de autor convidado submetido em 15 jul. 2019. Publicado em 30 jul. 2019.

** Doutora em Direito Previdenciário pela Pontifícia Universidade católica de São Paulo, São Paulo, Brasil / cristina@cristinaaguiar.adv.br
} 
Para isso, serão abordados a ideia de direitos sociais a partir da estrutura da seguridade social, como pilar da ordem social na Constituição Federal de 1988, a sua forma de financiamento e como construir a perspectiva de equilíbrio nessa matéria.

\section{DA ORDEM SOCIAL NA CONSTITUIÇÃO FEDERAL DE 1988}

A Constituição Federal de 1988 é reconhecida internacionalmente como uma das Cartas Constitucionais de maior alcance protetivo. Ao mesmo tempo que estabelece normas inerentes ao princípio da liberdade, tais como a liberdade de ir e vir, liberdade religiosa, liberdade de expressão, pressupõe que o exercício desses direitos negativos - por exigir uma postura omissiva do Estado não pode ser plenamente desenvolvido quando não há parâmetros mínimos de igualdade.

Esses parâmetros abarcam várias questões humanas que mereciam a proteção estatal aqui em uma postura positiva, pelo implemento de políticas públicas -, chamados pela Carta Magna de direitos sociais. Foram incluídos nesse rol a educação, a saúde, a alimentação, o trabalho, a moradia, o transporte, o lazer, a segurança, a previdência social, a proteção à maternidade e à infância e a assistência aos desamparados.

Compatível com a efetivação desses direitos, o texto constitucional, ao tratar em seu título Título VIII da Ordem Social, afirma, no art. 193, que "A ordem social tem como base o primado do trabalho, e como objetivo o bem-estar e a justiça sociais". O primado do trabalho, como esclarece Marcus Orione Golçalves Correia, traz a necessidade do resgate dos propósitos humanistas dos direitos sociais, o que perpassa pela liberdade do trabalhador e pela construção de um nível de solidariedade no ambiente de trabalho ${ }^{1}$.

Certo é que, na sociedade brasileira, o trabalho é o que permite ao ser humano a dignidade pela obtenção dos recursos para a garantia de sua subsistência e de sua família e; ao assim fazer, o indivíduo colabora com toda sociedade para o desenvolvimento econômico. Contudo, na realidade de um país ainda em desenvolvimento, como o Brasil, a estrutura protetiva do trabalhador não consegue evitar os abusos e ilegalidades no ambiente de trabalho expondo a pessoa ainda mais riscos do que está exposto na vida cotidiana.

A existência de riscos que podem afastar a pessoa de seu trabalho e, consequentemente, colocá-la em maior vulnerabilidade social, é o que estabelece a necessidade da construção de ações e políticas públicas capazes de reduzi-los. O que se pretende, nessa linha, é permitir o desenvolvimento social mesmo em momentos de impossibilidade de trabalho, seja pela ausência de oferta, seja pela ocorrência de um dos riscos sociais que impedem a execução da atividade laboral.

\footnotetext{
${ }^{1}$ CANOTILHO [et. al.]. Comentários à Constituição do Brasil. São Paulo: Saraiva, 2013. p. 1902. 
Com o desenvolvimento tecnológico, os riscos aos quais estão expostos os trabalhadores são mais complexos, resultando, não raras vezes, que na tentativa de diminuir os seus efeitos ou até mesmo elidi-los, outros riscos sejam criados $^{2}$. Mas, também, não se descarta o fato de que nenhuma conduta é livre de risco ${ }^{3}$.

No aspecto social, o risco assume papel mais relevante, pois repercute diretamente na proposta de qual sociedade se quer construir e na ideia de solidariedade para que o desenvolvimento seja possível. Trata-se de algo que, ao recair diretamente sobre a pessoa, pode impedi-la de trabalhar, afastando sua fonte de subsistência e, em decorrência, retirando-lhe elementos essenciais ao seu conceito de dignidade.

Hespana e Carapinheiro afirmam que um "um efeito particularmente visível de globalização consiste na emergência ou na amplificação de situações de risco social, através de processos por vezes muito complexos de ruptura dos equilíbrios sociais à escala local"4. Essa situação, por si só, é suficiente para uma reflexão de como gerenciar tais riscos.

Paul Durand, em sua obra La Política Contemporanéa de Seguridad Social, conceitua risco social da seguinte maneira:

La noción genérica de riesgo há sido ya precisada por el Derecho del Seguro, em donde se considera como tal a todo o acontecimento futuro e incierto, cuya actualización no depende exclusivamente de la voluntad del assegurado.

El Riego es um acontecimento infortunado la mayor parte de las veces: la enfermedad, la muerte (si se trata de um riesgo que afecte a la persona assegurada), el incêndio (si se trata de um bien material)... Em esos casosadopta el nombre de siniestro. Pero el calificativo de Riego también puedeaplicarse a acontecimentos venturosos: la supervivência del assegurado, em casos del seguro de vida; el matrimonio, o el nacimiento de um hijo, em los seguros de nupcialidad o natalidade $(\ldots)^{5}$.

Os riscos sociais assumem especial significado a partir do fortalecimento do conceito de seguridade social, primeiro ponto tratado no referido Título da Constituição Federal. A seguridade social é instrumentalizada por um sistema que tem por objetivo a proteção do indivíduo diante dos infortúnios da vida ${ }^{6}$. Como esclarece Wagner Balera:

A Ordem Social, diz o art. 193 - Disposição Geral que abre aquele Título da Constituição -, objetiva o bem-estar e a justiça sociais e com essas conquistas,

\footnotetext{
${ }^{2}$ BECK, Ulrich. Sociedade de risco mundial: em busca da segurança perdida. Lisboa: Edições 70, 2015 . p. 22.

${ }^{3}$ LUHMANN, Niklas. Sociología del riesgo. México: Universidad Iberoamericana, 2006. p. 73.

${ }^{4}$ HESPANA, Pedro e CARAPINHEIRO, Graça. A globalização do risco social: Uma introdução. In SANTOS, Boaventura de Sousa (dir.). Risco Social e incerteza: pode o estado social recuar mais?. Porto: Edições Afrontamento, 2002. p. 13.

${ }^{5}$ DURAND, Paul. La política contemporánea de Seguridad Social. Coleccion Seguridad Social, no 4. Madrid: Centro de Publicaciones Ministerio de Trabajo y Seguridad Social, 1991. p. 55.

${ }^{6}$ BERBEL, Fabio Lopes Vilela. Teoria Geral da Previdência Social. São Paulo: Quartier Latin, 2005. p. 122.
} 
provocar uma autêntica reviravolta nas políticas econômicas e sociais, desde aquelas que se destinam a preparar o terreno para a consagração dos objetivos do pleno emprego e da livre iniciativa (art. 170, da Constituição) até o advento da Justiça Social.

O art. 195, da Lei Suprema, não cogita - por ser incompatível com os claros termos da Ordem Social - de regressão das conquistas sociais já elevadas à dignidade constitucional.

Ao reverso, o preceito só conta com providências aptas de garantir a manutenção e a expansão da proteção social.

(...)

Esse é o verdadeiro sentido e alcance dos programas de proteção social. Seu destino e vocação consistem na promoção do bem de todos; na redução das desigualdades na rede erradicação da pobreza.

Propostas que só se implementam mediante aperfeiçoamento e não deformação das estruturas tão bem engendradas pelo constituinte de $1988 .^{7}$

Portanto, deve-se ter claro que os riscos sociais a serem previstos e que ensejam benefícios ou serviços sociais decorrem de uma construção e decisão política. Não foi diferente o que ocorreu com o texto constitucional de 1988.

A proteção social construída pela Constituição Federal de 1988, que vem aos poucos sendo mitigada por reformas que se afastam da história nacional e das lutas sociais, ainda é, mesmo com seu processo político de precarização, um dos instrumentos que mais induzem a diminuição das desigualdades sociais.

Mesmo com o afastamento cada vez mais frequente do intento do Constituinte originário, ainda é possível identificar a estrutura anteriormente idealizada de seguridade social, baseada em um conjunto de ações que englobam a Saúde, a Assistência Social e a Previdência Social.

A Saúde, estruturada em um sistema único e universal, tem como objetivo, a partir de ações preventivas e curativas (repressivas e protetivas) diminuir as ocorrências que afetam a saúde das pessoas, sejam elas trabalhadoras ou não. Trata-se de direito fundamental sem o qual o exercício dos demais fica prejudicado, já que afeta a premissa básica do ser humano: a vida.

O art. 196 da Constituição Federal afirma que "A saúde é direito de todos e dever do Estado, garantido mediante políticas sociais e econômicas que visem à redução do risco de doença e de outros agravos e ao acesso universal e igualitário às ações e serviços para sua promoção, proteção e recuperação."

O risco social amplo das prestações de saúde no modelo adotado pelo Brasil, em razão do seu caráter universalista, não prejudica a ideia inerente ao princípio da seletividade e distributividade a que está adstrita a Seguridade Social, apenas estabelece que a premissa básica do direito à igualdade exige, independente de quem seja o beneficiário, acesso real às possibilidades da vida, ao trabalho, às liberdades, o que não é possível sem o mínimo de atenção à saúde.

\footnotetext{
${ }^{7}$ BALERA, Wagner. Noções preliminares de Direito Previdenciário. 2a ed. rev. e ampl. São Paulo: Quartier Latin, 2010. p. 302 .
} 


\section{Como esclarecem Wagner Balera e Thiago Fernandes,}

(...) a ação de saúde é protegida pelo ordenamento jurídico, no exato momento em que o estado físico ou mental saudável é afetado ou ameaçado, incumbindo ao Poder Público restabelecê-lo ou preservá-lo. É a alteração ou ameaça de alteração do estado físico ou mental saudável que instaura o nascimento automático de uma relação jurídica entre o indivíduo e o Poder Público.

(...)

A saúde, como estado físico ou mental, não pode ser objeto da relação jurídica, porque esta não é uma obrigação de fim, mas sim de meio. Não se pode exigir do Poder Público a saúde (estado físico ou mental) como um bem material disponível. Exige-se dos poderes constituídos uma ação capaz de proporcionar aquele estado físico ou mental, mas não o próprio estado saudável. Somente, é possível exigir-se um serviço (direito público subjetivo), que possa proporcionar saúde (estado físico) ${ }^{8}$.

Desse modo foi estruturado no Brasil o Sistema Único de Saúde, permitindo a todos não só àqueles que se enquadrassem na ideia de trabalhador -, independente de contribuição, o amparo pelo Estado quando, em decorrência de evento vinculado à saúde, fossem colocados em risco de vulnerabilidade social. Nessa linha se inserem, por exemplo, o atendimento pré-natal à gestante, o sistema de vacinação e o atendimento ao idoso, mesmo que este já receba benefício de outra natureza (assistencial ou previdenciário). Das três áreas que compõem a seguridade social, a Saúde é a que tem abordagem e alcance mais amplos.

A Assistência Social, por sua vez, é o melhor exemplo da solidariedade, pois tem como foco a "proteção de todos os indivíduos, contra estados de necessidades, independentemente de contribuição"9 . De forma diversa não poderia ocorrer. Em países em desenvolvimento, como é o caso brasileiro, a vulnerabilidade social, em regra (que comporta exceções como, por exemplo, a drogadição e ocorrência de efeitos climáticos extremos), está atrelada à baixa renda, que coloque em risco a própria subsistência do ser humano.

Não é por outra razão que o art. 203 da Constituição Federal estabelece que:

Art. 203. A assistência social será prestada a quem dela necessitar, independentemente de contribuição à seguridade social, e tem por objetivos:

I - a proteção à família, à maternidade, à infância, à adolescência e à velhice;

II - o amparo às crianças e adolescentes carentes;

III - a promoção da integração ao mercado de trabalho;

IV - a habilitação e reabilitação das pessoas portadoras de deficiência e a promoção de sua integração à vida comunitária;

V - a garantia de um salário mínimo de benefício mensal à pessoa portadora de deficiência e ao idoso que comprovem não possuir meios de prover à própria manutenção ou de tê-la provida por sua família, conforme dispuser a lei.

\footnotetext{
${ }^{8}$ BALERA, Wagner; FERNANDES, Thiago D’Avila. Fundamentos da Seguridade Social. São Paulo: LTr, 2015. p. 168 e 169 .

${ }^{9}$ BALERA, Wagner; FERNANDES, Thiago D’Avila. Fundamentos da Seguridade Social. São Paulo: LTr, 2015. p. 168 e 169.
} 
Exigir, nessas condições, a contribuição para a obtenção de benefício assistencial, resultaria em uma descaracterização de sua natureza e de uma redução de alcance extremo. Por essa razão, ao lado da saúde, a assistência social dispensa a existência de contribuição para a utilização das prestações sociais, sejam elas na forma de serviço ou de renda.

Por fim, completa o conceito de seguridade social a previdência social, destinada somente a um grupo específico de pessoas que têm como característica comum o exercício de algum trabalho e estarem submetidas a riscos sociais previamente estabelecidas que as expõem à possibilidade de não terem condições de exercer atividade que viabilize seu sustento e de sua família.

Como resultado dessa preocupação constitucional, há a criação de benefícios e serviços prestados tanto ao segurado (trabalhador vinculado ao sistema previdenciário) quanto aos seus dependentes, nos termos definidos em lei. Por buscar a proteção de pessoas que possuem condições de sustento, o sistema prevê a contribuição obrigatória em um regime solidário, de forma a garantir benefícios que diminuam os impactos de riscos, não restritos apenas à idade avançada.

A contribuição somente é facultativa - mas dela depende o segurado para a vinculação ao sistema - àqueles que não exercem atividade que se caracteriza tipicamente como trabalho, a exemplo da dona de casa e do estudante que recebe bolsa de estágio.

Cada um desses braços da seguridade social busca a efetivação dos direitos sociais a partir de políticas públicas que possibilitem a diminuição das desigualdades sociais. Com focos diferentes que se entrelaçam e complementam, as ações voltadas à saúde, assistência e previdência social servem para viabilizar a justiça social tão almejada pelo art. 193 da Constituição Federal.

Contudo, esse nobre propósito necessita de amparo financeiro que viabilize as ações necessárias à efetivação da proteção social. O Estado obtém receitas a partir da arrecadação tributária, e, quanto maior for a rede de proteção social, maiores tendem a ser os gastos com políticas públicas. Por essa razão, deve-se identificar o ponto de equilíbrio entre custeio das prestações sociais e a ordem social estabelecida em 1988.

\section{DO CUSTEIO DA SEGURIDADE SOCIAL}

Ao tratar da seguridade social, a Constituição Federal estabeleceu, no art. 194, que a sua organização compete ao Poder Público, tendo por objetivos a universalidade da cobertura e do atendimento, a uniformidade e equivalência dos benefícios e serviços às populações urbanas e rurais, a seletividade e distributividade na prestação dos benefícios e serviços, a irredutibilidade do valor dos benefícios, a equidade na forma de participação no custeio, a diversidade da base de financiamento e o caráter democrático e descentralizado da administração, mediante gestão quadripartite, com 
participação dos trabalhadores, dos empregadores, dos aposentados e do Governo nos órgãos colegiados.

A equidade na forma de participação, para Miguel Horvath Júnior e Rafael Vasconcelos Porto, é “um princípio que tem o objetivo de justiça na delimitação da forma de participação de todos aqueles que devem contribuir para o sistema. Todos os membros da sociedade contribuem para o sistema de acordo com sua capacidade contributiva" ${ }^{10}$. Trata-se de típica demonstração do princípio da solidariedade, pois a sociedade como um todo participa para viabilizar o sistema.

Além disso, ampara a existência de contribuições diferenciadas para aqueles membros que, em razão do maior risco de sua atividade, têm maior chance de adoecer ou sofrer acidentes. Isso se dá pela alíquota diferenciada da atividade exercida em condições especiais de exposição ao risco, bem como pelo Seguro Acidente do Trabalho - SAT e pela aplicação do Fator Acidentário de Prevenção - FAP.

Ao mesmo tempo, considerando as limitações orçamentárias e financeiras existentes, foi prevista no texto constitucional (art. 195, $\S 5^{\circ}$ ), a regra da contrapartida, que determina que nenhum benefício pode ser criado ou majorado sem fonte prévia de custeio.

Wagner Balera explica que "Temos considerado que essa diretriz, que denominamos regra da contrapartida, desvela a preocupação do legislador constituinte, vedando a criação de benefícios ou serviços sem a previsão da fonte de custeio, com o equilíbrio financeiro do sistema de proteção social"11. A medida visa evitar o desequilíbrio do sistema pela criação incontrolada de benefícios sem a responsabilidade fiscal necessária.

O financiamento da seguridade social foi desenvolvido pelo art. 195 da Carta, que assim prevê:

Art. 195. A seguridade social será financiada por toda a sociedade, de forma direta e indireta, nos termos da lei, mediante recursos provenientes dos orçamentos da União, dos Estados, do Distrito Federal e dos Municípios, e das seguintes contribuições sociais:

I - do empregador, da empresa e da entidade a ela equiparada na forma da lei, incidentes sobre: (Redação dada pela Emenda Constitucional no 20, de 1998)

a) a folha de salários e demais rendimentos do trabalho pagos ou creditados, a qualquer título, à pessoa física que lhe preste serviço, mesmo sem vínculo empregatício; (Incluído pela Emenda Constitucional no 20, de 1998)

b) a receita ou o faturamento; (Incluído pela Emenda Constitucional no 20, de 1998)

c) o lucro; (Incluído pela Emenda Constitucional no 20, de 1998)

II - do trabalhador e dos demais segurados da previdência social, não incidindo contribuição sobre aposentadoria e pensão concedidas pelo regime geral de previdência social de que trata o art. 201; (Redação dada pela Emenda Constitucional $\mathrm{n}^{\mathrm{o}} 20$, de 1998)

\footnotetext{
${ }^{10}$ HORVATH JUNIOR, Miguel; PORTO, Rafael Vasconcelos. Teoria Geral do Plano de Custeio da Seguridade Social. In FERNANDES, Ana Paula (coord.). [et. al.]. Temas Relevantes e Pontos Controvertidos do Direito Previdenciário. São Paulo: LTr. p. 177.

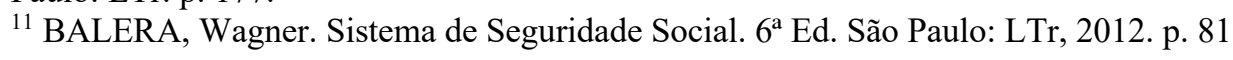


III - sobre a receita de concursos de prognósticos.

IV - do importador de bens ou serviços do exterior, ou de quem a lei a ele equiparar. (Incluído pela Emenda Constitucional nº 42, de 19.12.2003) (...).

Considerando que duas (assistência social e saúde) das três partes que compõem a seguridade social não possuem contribuições diretas do usuário, bem como a abrangência dos serviços e benefícios, a Constituição Federal foi feliz ao prever fontes diversificadas de financiamento para garantir que, mesmo diante de oscilações econômicas, os efeitos no lastro da seguridade social não chegassem a ser críticos.

Assim, previu como fontes ordinárias de receita direta as contribuições sociais recolhidas pelo empregador, tomador de serviço e do empregado ou prestador de serviço sobre a folha de pagamentos, tributos oriundos da receita ou faturamento e do lucro, como é o caso da CSLL e do PIS e COFINS, bem com parte das receitas das loterias e contribuições sociais do importador sobre bens ou serviços do exterior. Restou prevista também a fonte indireta de receitas para a seguridade social decorrente do repasse dos orçamentos da União, Estados e Municípios para o sistema securitário.

Trata-se, portanto, de sistema complexo, que prevê bases diversificadas para custeio de uma rede de benefícios que englobam os mais variados riscos aos quais a pessoa está submetida durante a vida, em suas mais variadas fases. E é nessa realidade que a seguridade social está inserida e deve ser considerada.

Obviamente, corresponde a uma política pública que exige grande volume de recursos, em quantidade condizente ao tamanho dos problemas que o Brasil vive e ao tamanho de suas desigualdades sociais. A busca do equilíbrio pode parecer distante ou inalcançável, mas talvez seja mais um problema de perspectiva do que efetivamente financeiro.

\section{A BUSCA DO EQUILÍBRIO}

A seguridade social no Brasil na forma prevista pela Constituição Federal de 1988 decorre da assunção pelo texto constitucional de uma linha condizente com o Estado de Bem-Estar Social, modelo que já havia sido adotado por vários países do mundo de forma mais ostensiva após a Segunda Guerra Mundial e tinha como base a ideia de diminuição das desigualdades sociais.

Oscar Vilhena Vieira explica as consequências normativas desse modelo ao afirmar que:

A Constituição Federal de 1988 é uma das representantes mais típicas do constitucionalismo de caráter social ou dirigista, que se iniciou com a Constituição mexicana de 1917 e a Constituição de Weimar de 1919. Diferentemente das Constituições liberais - que buscavam limitar o Estado assegurando o maior espaço de liberdade para o mercado -, as Constituições sociais organizam um Estado que 
visa a promover o bem-estar da sociedade, sendo, portanto, necessariamente mais amplas do que as Constituições liberais clássicas. ${ }^{12}$

Adotando essa linha, o modelo de seguridade social brasileiro teve como importante referência o Plano de Beveridge, baseado no atendimento de três objetivos, assim desenvolvidos:

To prevent interruption or destruction of earning power from leading to want, it is necessary to improve the present schemes of social insurance in three directions: by extension of scope to cover persons now is excluded, by extension of purposes to cover risks now excluded, and by raisingthe rates of benefit. ${ }^{13}$

Como se depreende do texto transcrito, a ideia de seguridade social somente seria possível a partir de uma preocupação de ampliação da proteção social pelo atendimento de cada vez mais pessoas, a ampliação dos riscos que seriam objeto de proteção e a criação de formas de garantir o seu financiamento.

A seguridade social não existe, nesse contexto, como uma mera política pública, mas sim com um intuito maior e mais nobre que é alcançar a justiça social. Esse preceito é fundamento do Estado Democrático de Direito desenhado pelo texto constitucional quando valoriza a ideia de uma sociedade justa e fraterna.

Uma finalidade tão nobre dificilmente poderia ser alcançada sem um esforço conjunto de toda a sociedade, de um maior comprometimento com o outro, como ser humano, e como tal, detentor de direitos. E é nessa realidade que aparece a seguridade social: ela busca a criação dos elementos mínimos que permitam a dignidade da pessoa humana, representante máximo de todo o arcabouço de direitos conhecido como direitos humanos.

A colocação do ser humano no centro de toda discussão jurídica, inevitavelmente, traz luz à dignidade da pessoa humana e a construção de um arcabouço normativo que possibilite a sua efetivação. Jorge Miranda desenvolve a questão ao afirmar que:

A Constituição, a despeito de seu caráter compromissório, confere uma unidade de sentido, de valor e de concordância prática ao sistema de direitos fundamentais. E ela repousa na dignidade da pessoa humana, proclamada no art. $1^{\circ}$, ou seja, na concepção que faz da pessoa fundamento e fim da sociedade do Estado.

Pelo menos, de modo direto e evidente, os direitos, liberdades e garantias pessoais e os direitos econômicos, sociais e culturais têm a sua fonte ética na dignidade da pessoa, de todas as pessoas. Mas quase todos os outros direitos, ainda quando projetados em instituições, remontam também a ideia de proteção e desenvolvimento das pessoas. A copiosa extensão do elenco não deve fazer perder de vista este referencial. ${ }^{14}$

\footnotetext{
${ }^{12}$ VIEIRA, Oscar Vilhena. A Constituição e a sua reserva de justiça. São Paulo: Malheiros Editores, 1999. p. 26.

${ }^{13}$ BEVERIDGE, William. Social Insurance and Allied Services. Londres: His Majesty's Stationnery Office, 1942. p. 7.

${ }^{14}$ MIRANDA. Jorge. Manual de Direito Constitucional, Tomo IV. $3^{\text {a }}$ ed. Coimbra: Coimbra, 1988, p. 180-181.
} 
A seguridade social, dentro desse contexto maior, leva em consideração que a ocorrência dos riscos sociais que impedem o exercício de uma atividade laboral afasta a pessoa da melhor ideia de dignidade social. Na típica realidade brasileira de um país em desenvolvimento, a construção dessas redes de proteção - principalmente por ter foco na garantia do mínimo existencial - tende a construir as situações que mais se aproximam do conceito de justiça social.

Jorge Reis Novais afirma que “(...) sob pena de esvaziamento normativo completo daqueles direitos ou princípios, o que seria incompatível com a natureza constitucional dos respectivos comandos de garantia, a conclusão lógica será a de que, em qualquer das hipóteses a que se adira, pelo menos um mínimo estará sempre constitucionalmente garantido ${ }^{15 \%}$. Embora se refera ao texto constitucional português, o raciocínio desenvolvido é apropriado à realidade brasileira.

Por isso, a existência, no texto constitucional, de amplo rol de benefícios vinculados à seguridade social, não pode ser vista apenas como uma imposição normativa, mas sim, como esclarece Solon Eduardo Annes Viola, “(...) têm sido, ao longo da história, uma construção dos múltiplos movimentos sociais, e não o resultado de um ordenamento jurídico ou o efeito de uma declaração"l6.

A proteção social desenvolvida na Constituição Federal de 1988 não é resultado da imposição normativa, mas sim de um pacto social firmado em um processo de transição relevante vivido pelo país. Oscar Vilhena Vieira desenvolve a questão da decisão no processo constituinte ao afirmar que:

As Constituições modernas, como resultantes de um processo constituinte, surgem a partir das ideias de racionalidade e igualdade propostas pelos jusnaturalistas. $\mathrm{O}$ direito natural, no entanto, não conseguiu se recuperar completamente das críticas de Hume. A contradição entre o direito natural e a necessidade humana de construção convencional de sua própria forma de governo está presente desde Hobbes, passando por Locke e Rousseau. A lei, que deveria derivar de uma razão natural, a partir do contratualismo passa, de fato, a resultado da vontade humana. Para alguns dos fundadores da nova nação americana o direito natural consistia apenas em uma ideia reguladora: visto como um paradigma a partir do qual se pudesse pensar os limites ideais ao exercício da autoridade, transformando-a em arranjos institucionais concretos. Nesse passo, a ideia de que o poder só poderia ser imposto a partir do consentimento concreto prevalece. Para os republicanos o direito deve ser fruto de procedimentos coletivos de deliberação, e não de uma abstração, da qual deriva uma forma ideal de governo.

É no marco da teoria do contrato social, portanto, que surge a ideia de poder constituinte. Esse é o substrato humano - mais do que isto, coletivo e democrático que substituirá o grande legislador mitológico ainda presente em Rousseau, capaz de descobrir as leis da natureza. ${ }^{17}$

\footnotetext{
${ }^{15}$ NOVAIS, Jorge Reis. Direitos Sociais: teoria jurídica dos direitos sociais enquanto direitos fundamentais. Coimbra: Coimbra Editora, 2010, p. 191 e 192.

${ }^{16}$ VIOLA, Solon Eduardo Annes. Direitos humanos e democracia no Brasil. São Leopoldo: Unisinos, 2008. p. 41.

${ }^{17}$ VIEIRA, Oscar Vilhena. A Constituição e a sua reserva de justiça: um ensaio sobre os limites materiais ao poder de reforma. São Paulo: Malheiros editores, 1999. p. 41 e 42.
} 
O modelo de seguridade social adotado na Constituição Federal de 1988, que escolhe uma quantidade importante de riscos sociais, mais do que a definição de normas impositivas é o resultado de escolhas sobre um futuro, de um país que ser queria (e ainda se quer) construir.

A partir dessa percepção, os altos valores envolvidos na viabilização das políticas públicas de seguridade social, exigindo a participação de toda a sociedade na sua concretização, não se mostram um custo ou uma despesa, mas sim o financiamento de um futuro melhor, um investimento.

A importância da seguridade social e a consciência de uma estrutura protetiva de direitos tão relevante para a justiça social não afastam, contudo, a preocupação de que os recursos oriundos de toda a sociedade sejam bem geridos e sua utilização otimizada. Isso não pode ser argumento, também, para o desmantelamento das políticas públicas, como é possível verificar em alguns discursos que vendem a ideia de que todo o beneficiário é, em última análise, um fraudador.

É por essa razão que o objetivo de realização de justiça social deve ser sempre o foco da análise da questão, a partir da construção de que a dignidade da pessoa humana só é possível pela coexistência harmônica de todas as dimensões de direitos do ser humano e pela sua efetivação. Heiner Bielefeldt desenvolve a relação entre as dimensões de direitos ao afirmar que:

Liberdade, igualdade e solidariedade formam uma fórmula estrutural que somente faz sentido se os três aspectos tiverem uma unidade interna. Os três componentes não estão apenas juntos aditivamente ou, até, em contraposição, mas esclarecem-se reciprocamente. Eles não estabelecem uma relação de recíproca complementação ou relativização, mas sim, uma relação de recíproco esclarecimento. No sentido dos direitos humanos, não pode haver liberdade sem igualdade; se assim não fosse, a liberdade seria apenas privilégio e não direito humano. A recíproca também é verdadeira: uma igualdade que não seja direcionada à liberdade não pode ser considerada princípio de direito humano, pois nesses direitos sempre importa o reconhecimento político e jurídico da autonomia responsável. Que a autonomia responsável existe dentro do direito à liberdade igual para todos, não possa referirse a indivíduos isolados, esclarece-se através do conceito de solidariedade, que também engloba a responsabilidade comunitária por uma ordem libertária política com participação paritária. ${ }^{18}$

Essa necessidade de análise conjunta de direitos é levada a cabo pela forma como foi estruturada a ordem social. Essa ordem, deve-se ainda destacar, não consegue - nem seria possível abarcar a complexidade cada vez maior dos riscos sociais a que o ser humano está sujeito, o que ela faz é delimitar os riscos considerados relevantes a serem protegidos.

Se esses riscos seguem compondo uma ampla lista, essa é apenas a fotografia de um Estado que ainda não conseguiu diminuir suas desigualdades sociais a patamares que permitam a reconfiguração do risco, pela mudança da realidade social. Para Wagner Balera “(...) a pós-

\footnotetext{
${ }^{18}$ BIEFELDT, Heiner. Filosofia dos Direitos Humanos. Trad. Dankwart Bernsmuller. São Leopoldo: Ed. UNISINOS, 2000. p 115 e 116.
} 
modernidade apontou distintas dimensões para os mesmos riscos e, em sua marcha acelerada, não se cansa de propor novos horizontes, que está a submeter a verdadeiro teste de eficácia todos os esquemas postos de proteção social."19

Por essa razão, embora haja um esforço indispensável de otimização e de diminuição dos gastos públicos nas políticas vinculadas à seguridade social, tal esforço não pode se dar pela mera escolha de ignorar que os riscos não foram mitigados ou superados ao longo dos anos.

A política pública de seguridade social necessita realmente de grande volume de recursos para seu financiamento, mas custo mesmo é o que o país enfrentará com o aumento das desigualdades sociais pelo esvaziamento dessas políticas públicas através das medidas que vêm sendo adotadas nos últimos anos. E quem está disposto a pagar essa conta?

\section{CONCLUSÃO}

A partir das premissas desenvolvidas, é possível afirmar que a Constituição Federal de 1988, ao estabelecer a seguridade social como um dos elementos da ordem social, que tem como base o trabalho, delimitou não somente ideias de políticas públicas a serem desenvolvidas, mas verdadeiros mandamentos que vinculam a atuação pública.

Longe de ser uma Carta imposta, o texto constitucional decorre da construção de lutas sociais que permitiram a transição de um estado de exceção no qual o Brasil vivia para uma democracia. Essa realidade histórica e social é relevante para delimitar claramente o intento político definido pela sociedade.

Ao trazer a proteção do trabalho como base da ordem social e amparar os riscos a que a pessoa estaria submetida em um sistema de seguridade social que abarca benefícios e serviços nas áreas de saúde, assistência e previdência social, a sociedade firmou um pacto para a construção do bem comum. Como lembra Wilson Engelmann, essa construção exige a "consciência moral de todos os envolvidos: sejam os particulares, sejam os representantes do poder público" ${ }^{20}$.

E uma política pública com tantos desdobramentos e repercussões dificilmente poderia ser efetivada com poucos recursos. Qualquer sistema de seguridade social que aborde tantos riscos diferentes exige, inevitavelmente, o desembolso de altas quantias por parte do Estado.

Contudo, ao colocar em uma balança, na busca do desejado equilíbrio, o valor despendido e os efeitos na diminuição das desigualdades sociais e na construção da tão sonhada sociedade justa e fraterna, qual resultado é obtido?

\footnotetext{
${ }^{19}$ BALERA, Wagner. Noções Preliminares de Direito Previdenciário. São Paulo: Quartier Latin, 2010. p.174.

${ }^{20}$ ENGELMANN, Wilson; FLORES, André. A phrónesis como mediadora ética para os avanços com o emprego das nanotecnologias: em busca de condições para o pleno florescimento humano no mundo nanotech. Revista da Ajuris, v. 36, 2009. p. 316.
} 
A discussão, de fato, foge do simples argumento financeiro e matemático e recai, necessariamente, sobre aquilo que não tem preço, mas sim dignidade, como bem delineava Kant ${ }^{21}$. Não se defende, também, a ignorância quanto ao fato de que os recursos são finitos, mas o estabelecimento do ponto em que se encontra a prioridade como sociedade. Afinal, o ponto principal é o ser humano ou os recursos financeiros que ele pode criar?

O fortalecimento dos direitos humanos e a construção de uma justiça social com diminuição das desigualdades sociais é, possivelmente, o melhor instrumento para a diminuição dos riscos sociais, ao mesmo tempo que no exercício da dignidade essas pessoas têm condições de exercer adequadamente seu trabalho gerando os recursos necessários para viabilizar as políticas públicas protetivas. O equilíbrio está, portanto, na colocação novamente do ser humano e sua dignidade no centro da pauta das discussões sobre a ordem social e a partir do qual o financiamento das políticas públicas deve ser construído.

\section{REFERÊNCIAS}

BALERA, Wagner; FERNANDES, Thiago D’Avila. Fundamentos da Seguridade Social. São Paulo: LTr, 2015.

BALERA, Wagner. Noções preliminares de Direito Previdenciário. $2^{\mathrm{a}}$ ed. rev. e ampl. São Paulo: Quartier Latin, 2010.

BALERA, Wagner. Sistema de Seguridade Social. 6a Ed. São Paulo: LTr, 2012.

BECK, Ulrich. Sociedade de risco mundial: em busca da segurança perdida. Lisboa: Edições 70, 2015.

BEVERIDGE, William. Social Insurance and Allied Services. Londres: His Majesty's Stationnery Office, 1942.

BERBEL, Fabio Lopes Vilela. Teoria Geral da Previdência Social. São Paulo: Quartier Latin, 2005.

BIEFELDT, Heiner. Filosofia dos Direitos Humanos. Trad. Dankwart Bernsmuller. São Leopoldo: Ed. UNISINOS, 2000.

CANOTILHO [et. al.]. Comentários à Constituição do Brasil. São Paulo: Saraiva, 2013.

DURAND, Paul. La política contemporánea de Seguridad Social. Coleccion Seguridad Social, no 4. Madrid: Centro de Publicaciones Ministerio de Trabajo y Seguridad Social, 1991.

\footnotetext{
${ }^{21}$ KANT, Immanuel. Fundamentação da Metafísica dos Costumes e outros escritos. São Paulo: Martin Claret, 2006. p.
} 65. 
ENGELMANN, Wilson; FLORES, André. A phrónesis como mediadora ética para os avanços com o emprego das nanotecnologias: em busca de condições para o pleno florescimento humano no mundo nanotech. Revista da Ajuris, v. 36, 2009.

HESPANA, Pedro e CARAPINHEIRO, Graça. A globalização do risco social: Uma introdução. In SANTOS, Boaventura de Sousa (dir.). Risco Social e incerteza: pode o estado social recuar mais?. Porto: Edições Afrontamento, 2002.

HORVATH JUNIOR, Miguel; PORTO, Rafael Vasconcelos. Teoria Geral do Plano de Custeio da Seguridade Social. In FERNANDES, Ana Paula (coord.). [et. al.]. Temas Relevantes e Pontos Controvertidos do Direito Previdenciário. São Paulo: LTr.

LUHMANN, Niklas. Sociología del riesgo. México: Universidad Iberoamericana, 2006.

MIRANDA. Jorge. Manual de Direito Constitucional, Tomo IV. $3^{\text {a }}$ ed. Coimbra: Coimbra, 1988.

NOVAIS, Jorge Reis. Direitos Sociais: teoria jurídica dos direitos sociais enquanto direitos fundamentais. Coimbra: Coimbra Editora, 2010.

VIEIRA, Oscar Vilhena. A Constituição e a sua reserva de justiça. São Paulo: Malheiros Editores, 1999.

VIOLA, Solon Eduardo Annes. Direitos humanos e democracia no Brasil. São Leopoldo: Unisinos, 2008. 